ARTIKEL PENELITIAN

\title{
Hubungan Derajat Nyeri dan Klasifikasi Radiologik dengan Kualitas Hidup Pasien Osteoartritis Lutut
}

\author{
Salma Nur Afina, ${ }^{1}$ Lelly Yuniarti, ${ }^{2}$ Sadeli Masria, ${ }^{3}$ \\ Hilmi Sulaiman Rathomi, ${ }^{4}$ Susanti Dharmmika ${ }^{5}$ \\ ${ }^{1}$ Program Studi Pendidikan Dokter, ${ }^{2}$ Bagian Ilmu Biomedik, ${ }^{3}$ Bagian Ilmu Mikrobiologi, ${ }^{4}$ Bagian Ilmu Kesehatan \\ Masyarakat, ${ }^{5}$ Bagian Kedokteran Fisik dan Rehabilitasi, Fakultas Kedokteran Universitas Islam Bandung
}

\begin{abstract}
Abstrak
Osteoartritis (OA) lutut merupakan masalah kesehatan masyarakat utama yang mengakibatkan nyeri dan disabilitas. Sampai saat ini masih belum jelas diketahui dampak penyakit OA lutut dilihat dari derajat nyeri dan klasifikasi radiologik OA dengan kualitas hidup pasien OA lutut. Tujuan penelitian ini adalah mengetahui hubungan derajat nyeri dan klasifikasi radiologik OA dengan kualitas hidup pasien OA lutut. Penelitian ini adalah studi analitik dengan pendekatan cross sectional. Sebanyak 85 pasien OA telah dipilih secara consecutive dan dinilai kualitas hidupnya yang terdiri atas delapan komponen menggunakan kuesioner $\mathrm{SF}-36$, derajat nyerinya menggunakan numeric rating scale (NRS), serta secara radiologik berdasar atas klasifikasi Kellgren-Lawrence (KL). Penelitian ini dilakukan di RS Al-Islam Bandung selama periode April-Juli 2018. Data dianalisis dengan SPSS melalui Uji Kruskal-Wallis. Dari hasil penelitian didapatkan mayoritas pasien OA lutut mengalami derajat nyeri sedang (50\%) termasuk dalam klasifikasi radiologik OA moderat (43\%) dan skor kualitas hidup $548(265,63-728,5)$. Penelitian ini menunjukkan hubungan bermakna antara derajat nyeri dan kualitas hidup pada aspek nyeri dan vitalitas $(\mathrm{p}=0,000$ dan 0,005$)$ serta hubungan klasifikasi radiologik OA dengan kualitas hidup aspek fungsi sosial $(p=0,027)$. Disimpulkan bahwa terdapat hubungan derajat nyeri dengan kualitas hidup pada aspek nyeri dan vitalitas serta hubungan klasifikasi radiologik OA dengan kualitas hidup pada aspek fungsi sosial.
\end{abstract}

Kata kunci: Derajat nyeri, klasifikasi Kellgren-Lawrence, kuesioner SF-36, osteoartritis lutut

\section{Radiographic Classification with Quality of Life in Knee Osteoarthritis Patient}

\begin{abstract}
Knee osteoarthritis (OA) is a major public health issue causing chronic pain and disability. Until now there is a little explanation on the impact of degree of pain and radiographic classification of OA on quality of life (QOL) in knee OA patient. The objective of this study was to clarify association between degree of pain and radiographic classification of OA with QOL in knee OA patient. A total of 85 knee OA patients were selected consecutively and assessed for their eight component of quality of life using the SF-36 questionnaire, their degree of pain using numeric rating scale (NRS), and radiologically based on the Kellgren-Lawrence (KL) classification. This research was conducted in RS Al-Islam Bandung during period of April-July 2018. Data were analyzed with SPSS through Kruskal-Wallis test. From the results of the study, the majority of OA patients experienced moderate pain degree (50\%) and were included in moderate OA classification (43\%) and QOL score of 548 (265.63-728.5). This study showed that there was a significant association between degree of pain and QOL on pain and vitality component $(\mathrm{p}=0.000$ and 0.005$)$ and association between OA radiographic classification and QOL in social functioning component $(\mathrm{p}=0.027)$. It can be concluded that there is association between degree of pain with QOL on pain and vitality component also association between radiologic classification of OA with QOL on social functioning component in knee OA patient.
\end{abstract}

Keywords: Degree of pain, Kellgren-Lawrence classification, knee osteoarthritis, SF-36 questionnaire

Korespondensi: Salma Nur Afina. Program Studi Pendidikan Dokter, Fakultas Kedokteran, Universitas Islam Bandung. Jl. Tamansari no. 22, 40116, Kota Bandung, Provinsi Jawa Barat. E-mail: salmanurafn@gmail.com 


\section{Pendahuluan}

Osteoartritis merupakan bentuk radang sendi yang paling sering ditemukan di masyarakat, bersifat kronis, dan berdampak besar dalam masalah kesehatan masyarakat. ${ }^{1}$ Berdasar atas Global Burden Disease Study 2010, diketahui prevalensi OA di seluruh dunia pada tahun 2004 mencapai 151,4 juta kasus, sedangkan di kawasan Asia Tenggara prevalensinya mencapai 27,4 juta kasus. ${ }^{2}$

Pada tahun 2015, prevalensi OA lutut yang tampak secara radiologik di Indonesia mencapai $15,5 \%$ pada pria dan $12,7 \%$ pada wanita usia $40-60$ tahun. Penelitian di Bandung pada pasien yang berobat ke Klinik Reumatologi RSHS pada tahun 2007 dan 2010, berturut-turut didapatkan: OA merupakan 74,48\% dari keseluruhan kasus (1.297) reumatik pada tahun 2007. Enam puluh sembilan persen di antaranya adalah wanita dan kebanyakan merupakan OA lutut (87\%). Dari 2.790 kasus reumatik pada tahun 2010, $73 \%$ di antaranya adalah penderita OA. ${ }^{1}$

Osteoartritis itu sendiri dapat didefinisikan berdasar atas gambaran klinis dan juga radiologik. Osteoartritis secara klinis didefinisikan berdasar atas karakteristik saat anamnesis dan pemeriksaan dengan ditemukannya rasa nyeri pada sendi. Osteoartritis secara radiologik diidentifikasi berdasar atas hasil temuan radiologiknya berupa osteofit, ruang sendi hilang, dan sklerosis. Osteoartritis secara radiologik diklasifikasikan berdasar atas tingkat keparahannya dengan mempergunakan Kellgren-Lawrence (KL) grading score menjadi lima derajat. ${ }^{3}$

Kejadian OA lutut lebih sering dibanding dengan kejadian OA panggul. ${ }^{3}$ Kejadian OA lutut merupakan masalah utama pada kesehatan masyarakat yang mengakibatkan nyeri kronik dan disabilitas. ${ }^{4}$ Gejala OA seperti rasa nyeri dan kaku yang kronik berkontribusi terhadap keterbatasan fungsional pada pasien OA. Nyeri yang menetap dan tidak terkontrol memiliki efek buruk terhadap kualitas hidup pasien karena dapat mengakibatkan gangguan emosi atau kecemasan, mengganggu kapasitas fungsional, dan menghalangi kemampuan untuk memenuhi peran dalam keluarga, sosial, dan pekerjaan. ${ }^{5}$

Nyeri dan kualitas hidup merupakan determinan kesehatan yang dapat diukur. Nyeri dapat diukur intensitasnya menggunakan beberapa alat pengukuran, salah satu yang paling sering dipakai adalah numeric rating scale (NRS) yang kemudian mengklasifikasikan nyeri menjadi derajat nyeri ringan, sedang, dan berat. ${ }^{6}$ Kualitas hidup dapat diukur melalui beberapa instrumen, di antaranya Short Form-36 (SF-36), Western Ontario and McMaster Universities Arthritis Index (WOMAC), World Health Organization Quality of Life (WHOQOL), dll. Salah satu yang paling sering digunakan untuk mengukur kualitas hidup adalah kuesioner SF-36 yang menilai kualitas hidup dilihat dari delapan komponen. ${ }^{7}$

Sementara dampak nyeri dengan kualitas hidup pasien OA telah sering diteliti, tetapi hubungan antara derajat klasifikasi radiologik OA dan kualitas hidup masih sedikit diketahui. ${ }^{8}$ Dari hasil penelitian kohort di Swedia Selatan menunjukkan bahwa pasien OA lutut dengan kelainan radiologik dan nyeri lutut memiliki kualitas hidup lebih rendah dibanding dengan pasien
OA lutut dengan kelainan radiologik saja. Hasil penelitian yang telah dilakukan di Jepang diketahui bahwa pasien OA lutut dengan klasifikasi KL 3 dan 4 disertai nyeri memiliki nilai kualitas hidup fisik yang lebih rendah daripada pasien dengan klasifikasi KL 3 dan 4 tanpa nyeri. 4

Dari penelitian yang telah dilakukan masih belum diketahui dengan jelas faktor mana yang memengaruhi kualitas hidup para pasien OA lutut berdasar atas klasifikasi radiologik OA dan derajat nyeri. Dengan demikian, tujuan penelitian ini adalah mengetahui hubungan derajat klasifikasi radiologik OA dan derajat nyeri dengan kualitas hidup pasien penderita OA.

\section{Metode}

Penelitian ini merupakan penelitian observasional analitik menggunakan desain penelitian cross sectional dengan metode pengambilan sampel consecutive sampling pada pasien OA lutut yang melakukan rawat jalan di RS Al-Islam Bandung dari bulan April-Juli 2018. Seluruh pasien sebelumnya telah disediakan formulir informed consent.

Seluruh pasien telah melaksanakan pemeriksaan $x$-ray pada lutut yang mengalami OA dengan hasil interpretasi menggunakan KL grading score menjadi derajat $\mathrm{KL} \mathrm{O}-4$, dan telah diketahui bahwa derajat lebih tinggi dihubungkan dengan bentuk OA yang lebih parah. Kuesioner SF-36 dipergunakan untuk mengukur kualitas hidup subjek penelitian. Kuesioner ini mengukur profil kesehatan individu dilihat dari delapan komponen yang terdiri atas fungsi fisik, keterbatasan akibat masalah fisik, rasa sakit/nyeri, persepsi kesehatan umum, energi/vitalitas, fungsi sosial, keterbatasan akibat masalah emosional, dan kesehatan mental. Pengukuran derajat nyeri dilakukan menggunakan alat ukur NRS dengan skala ukur nyeri 0-10 dan diklasifikasikan menjadi derajat nyeri ringan (0-3), sedang (4-6), dan berat (7-10).

Perangkat lunak SPSS dipergunakan untuk analisis data. Analisis deskriptif dilaksanakan untuk mengidentifikasi karakteristik peserta yang mengikuti penelitian. Uji hipotesis Kruskal-Willis dipergunakan untuk menganalisis hubungan derajat nyeri dan klasifikasi radiologik OA dengan kualitas hidup. Penelitian ini telah mendapatkan izin etik dari Komite Etik Kesehatan Fakultas Kedokteran Unisba dengan Nomor 230/Komite Etik FK/III/2018.

\section{Hasil}

Terdapat 85 pasien OA lutut yang telah melakukan pemeriksaan foto rontgen lutut mengikuti penelitian, didapatkan data sebagai berikut: dari 85 pasien $\mathrm{OA}$ lutut yang mengikuti penelitian ini sebagian besar pasien perempuan (87\%) dengan median usia 62 tahun dan telah menderita OA lutut $>1$ tahun (Tabel 1 ).

Berdasar atas Tabel 2 sebagian besar pasien mengeluhkan nyeri yang sedang (51\%) dan memiliki kelainan rontgen lutut dengan derajat OA moderat (44\%) dan OA minimal (33\%). Pada 85 responden pasien OA lutut diketahui bahwa median dari jumlah skor keseluruhan delapan komponen dari kuesioner kualitas hidup SF-36 adalah 548 dengan range $265,63-728,5$. 
Tabel 1 Karakteristik Pasien OA Lutut berdasar atas Jenis Kelamin, Usia, dan Lama Menderita OA

\begin{tabular}{lccc}
\hline \multicolumn{1}{c}{ Variabel } & Perempuan & Laki-laki & Keseluruhan \\
\hline Jumlah responden (n, \%) & $74(87 \%)$ & $11(13 \%)$ & 85 \\
Usia (median, min.-maks.) & $62(40-78)$ & $66(41-83)$ & $62(40-83)$ \\
Lama menderita OA & & & \\
$>1$ tahun (n, \%) & $50(68 \%)$ & $9(82 \%)$ & 59 \\
$<1$ tahun (n, \%) & $24(32 \%)$ & $2(18 \%)$ & 26 \\
\hline
\end{tabular}

Tabel 2 Distribusi Frekuensi Derajat Nyeri, Klasifikasi Radiologik OA, dan Kualitas Hidup

\begin{tabular}{|c|c|c|c|}
\hline Variabel & Perempuan $(n=74)$ & Laki-laki (n=11) & Keseluruhan $(n=85)$ \\
\hline \multicolumn{4}{|l|}{ Derajat nyeri } \\
\hline Ringan (n, \%) & $6(7 \%)$ & $3(3 \%)$ & $9(10 \%)$ \\
\hline Sedang (n, \%) & $38(45 \%)$ & $5(6 \%)$ & $43(51 \%)$ \\
\hline Berat (n, \%) & $30(35 \%)$ & $3(4 \%)$ & $33(39 \%)$ \\
\hline \multicolumn{4}{|l|}{ Klasifikasi Radiologik OA } \\
\hline Normal (n, \%) & $6(7 \%)$ & o (o\%) & $6(7 \%)$ \\
\hline Ragu-ragu (n, \%) & $11(13 \%)$ & $2(2 \%)$ & $13(15 \%)$ \\
\hline OA Minimal (n, \%) & $23(27 \%)$ & $5(6 \%)$ & $28(33 \%)$ \\
\hline OA Moderat (n, \%) & $33(39 \%)$ & $4(5 \%)$ & $37(44 \%)$ \\
\hline OA Berat (n, \%) & $1(1 \%)$ & o (o\%) & $1(1 \%)$ \\
\hline $\begin{array}{l}\text { Kualitas hidup (Median, } \\
\text { Min._-maks.) }\end{array}$ & $552,66(265,63-728,5)$ & $524(272,3-659,33)$ & $548(265,63-728,5)$ \\
\hline
\end{tabular}

Keterangan: total Skor Kualitas Hidup SF-36 = 800

Tabel 3 Total Skor Kualitas Hidup Tiap Kelompok Derajat Nyeri dan Klasifikasi Radiologik OA

\begin{tabular}{lc}
\hline Variabel & Total Skor $(\mathbf{n}=\mathbf{8 0 o})$ \\
\hline Derajat nyeri & \\
$\quad$ Ringan & $548(405,6-659,33)$ \\
Sedang & $579,17(330,1-728,5)$ \\
$\quad$ Berat & $516,33(265,63-701)$ \\
Klasifikasi radiologik OA & \\
Normal & $532,42(282,63-675,5)$ \\
Ragu-ragu & $605,34(308,1-701)$ \\
OA minimal & $521,5(265,63-659,33)$ \\
OA moderat & $541,17(272,3-728,5)$ \\
OA berat & 451,33 \\
\hline
\end{tabular}

Keterangan: hanya terdapat 1 responden pada kelompok OA berat 


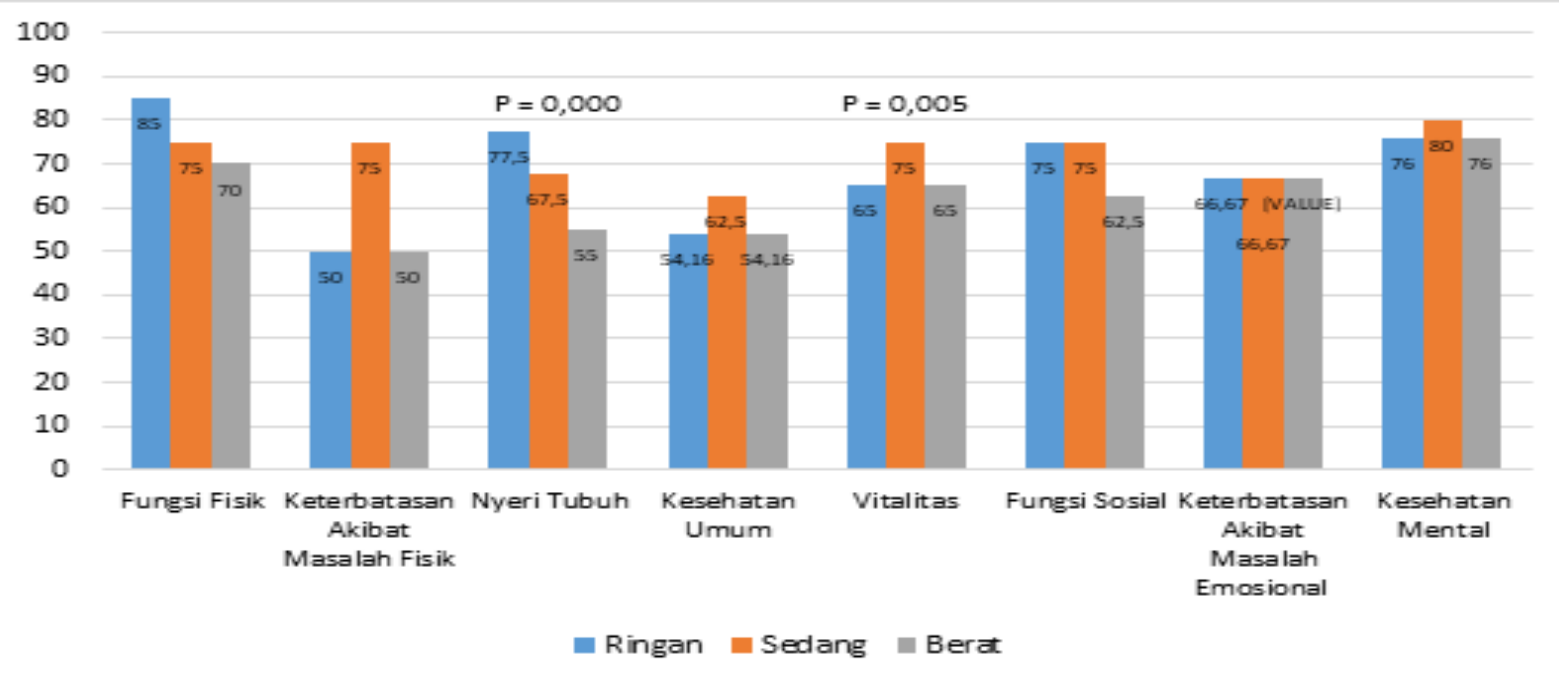

\section{Gambar 1 Hubungan Derajat Nyeri dengan Kualitas Hidup}

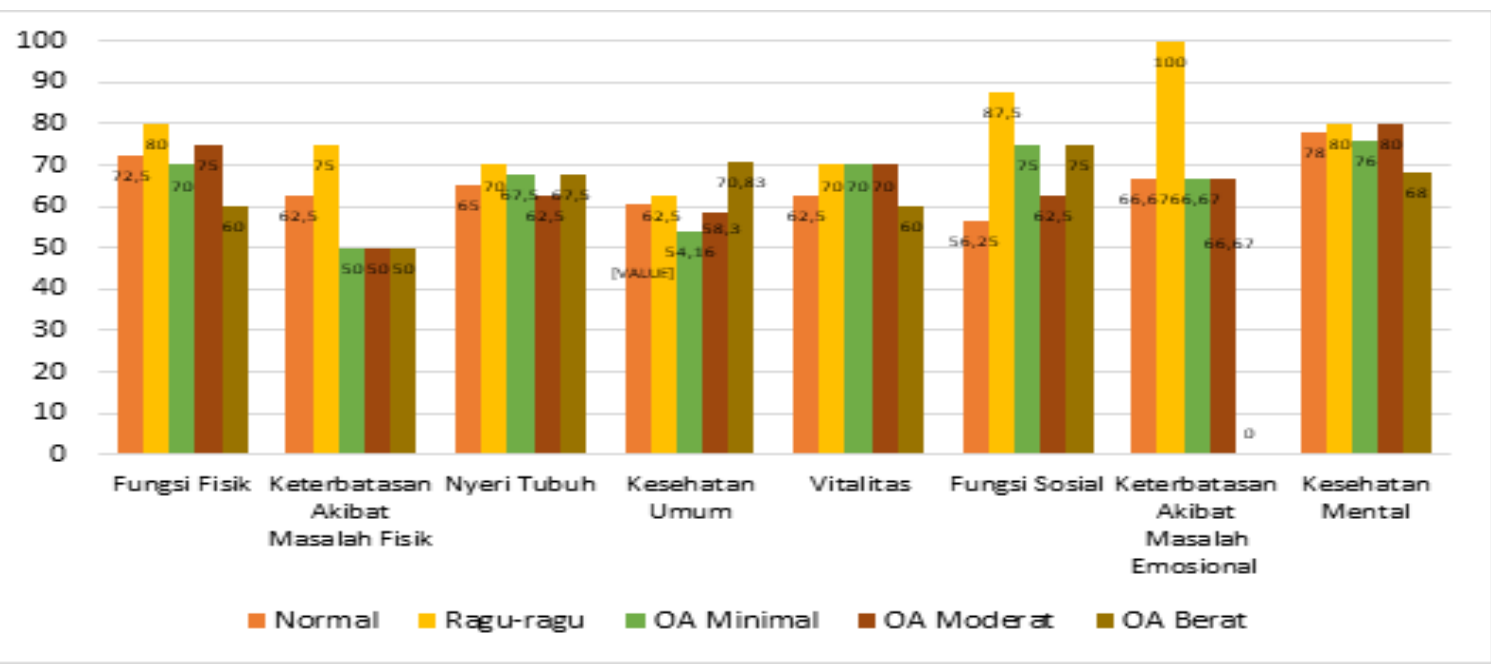

Gambar 2 Hubungan Klasifikasi Radiologik OA dengan Kualitas Hidup

Berdasar atas Tabel 3 tersebut diketahui bahwa total skor kualitas hidup paling rendah terdapat pada kelompok derajat nyeri berat dan klasifikasi radiologik OA berat dibanding dengan dengan kelompok lainnya.

Gambar 1 menunjukkan nilai median skor delapan komponen kualitas hidup dari kelompok derajat nyeri ringan, sedang, dan berat. Hasil dari perhitungan statistik menunjukkan nilai p yang bermakna (nilai alpha <0,05) pada komponen kualitas hidup nyeri tubuh dan vitalitas (nilai $\mathrm{p}=0,000$ dan 0,005 ). Pada komponen nyeri tubuh terlihat bahwa pasien OA lutut dengan derajat nyeri berat memiliki skor lebih rendah dibanding dengan pasien OA lutut dengan derajat nyeri sedang dan ringan. Komponen vitalitas terlihat bahwa pasien OA lutut dengan derajat nyeri berat memiliki skor yang sama dengan pasien OA lutut dengan derajat nyeri ringan, namun lebih rendah daripada pasien OA lutut derajat nyeri sedang.

Gambar 2 menunjukkan nilai median skor delapan komponen kualitas hidup dari klasifikasi radiologik OA normal, ragu-ragu, OA ringan, OA moderat, dan OA berat. Hasil perhitungan statistik hubungan klasifikasi radiologik OA dengan kualitas hidup pasien OA menunjukkan nilai p yang bermakna (nilai alpha $<0,05$ ) hanya pada komponen kualitas hidup fungsi sosial dengan nilai $\mathrm{p}=0,027$.

\section{Pembahasan}

Hasil penelitian menunjukkan bahwa pasien OA lebih banyak pada perempuan dan memiliki rerata usia 62 tahun. Hasil penelitian ini sesuai dengan penelitian 
Litwic dkk. ${ }^{3}$ yang menyatakan bahwa insidensi dan prevalensi OA pada pasien wanita lebih tinggi daripada pria serta meningkat sesuai dengan usia.

Dari 85 pasien OA lutut yang mengikuti penelitian ditemukan distribusi frekuensi derajat nyeri dan klasifikasi radiologik OA berdasar atas KL grading paling banyak ditemukan adalah derajat nyeri sedang dan klasifikasi OA moderat. Penelitian yang dilakukan oleh Lukum dkk. ${ }^{9}$ di Makassar mendapatkan bahwa distribusi frekuensi derajat nyeri diukur menggunakan visual analog scale (VAS) yang paling banyak ditemukan adalah derajat nyeri berat. Distribusi frekuensi klasifikasi radiologik OA berdasar atas KL paling banyak ditemukan adalah derajat III atau OA moderat.

Penelitian ini menunjukkan bahwa pasien OA lutut memiliki kualitas hidup yang relatif rendah dengan median total skor kualitas hidup seluruh delapan komponen adalah 548. Hasil penelitian ini sesuai dengan penelitian Kawano dkk. ${ }^{10}$ yang mengukur kualitas hidup pasien OA lutut menggunakan kuesioner SF-36. Penelitiannya menyatakan bahwa pasien OA memiliki persepsi yang rendah terhadap kualitas hidup terutama pada kapasitas fungsional, keterbatasan fisik, serta rasa nyeri. Pasien OA lutut mempunyai kecenderungan peningkatan keterbatasan fisik dan fungsional serta nyeri seiring dengan progresivitas penyakit. Progresivitas penyakit yang dirasakan pada pasien OA lutut tersebut berdampak terhadap aktivitas sehari-hari yang memicu hilangnya hubungan kerja, kenyamanan, kehidupan sosial, dan kualitas tidur yang kemudian memengaruhi penurunan kualitas hidup.

Hasil analisis hubungan antara derajat nyeri dan kualitas hidup pasien OA didapatkan nilai signifikansi pada komponen kualitas hidup nyeri tubuh dan vitalitas (nilai $\mathrm{p}=0,000$ dan 0,005 ). Seperti yang dicantumkan di dalam penelitian yang dilakukan oleh Katz ${ }^{5}$ bahwa terjadi penurunan yang signifikan skor kualitas hidup SF-36 di seluruh delapan komponen kualitas hidup pada pasien dengan derajat nyeri sedang dan berat dibanding dengan pasien derajat nyeri ringan.

Penelitian yang sudah dilaksanakan oleh Neogi ${ }^{12}$ dijelaskan bahwa gejala nyeri berkontribusi terhadap keterbatasan fisik pada pasien OA lutut terutama dalam hal menurunkan kekuatan dan aktivitas sendi. Hal ini mengakibatkan prevalensi disabilitas pada pasien OA lutut dengan nyeri tinggi. Keterbatasan fisik akibat nyeri yang terjadi pada pasien OA lutut dapat memengaruhi aktivitas sehari-hari dan partisipasi sehingga dapat menurunkan kualitas hidup baik dalam komponen fisik maupun mental.

Hasil analisis berdasar atas hubungan antara klasifikasi radiologik OA dan kualitas hidup pasien OA didapatkan nilai signifikansi hanya pada komponen kualitas hidup fungsi sosial $(\mathrm{p}=0,027)$. Hasil penelitian ini berbeda dengan penelitian yang dilakukan Muraki dkk. ${ }^{4}$ menyatakan bahwa skor komponen mental dalam kuesioner SF-36 yang terdiri atas fungsi sosial, keterbatasan karena masalah sosial, dan kesehatan mental relatif lebih tinggi pada pasien OA dengan klasifikasi radiologik $\mathrm{KL} 3-4$ dibanding dengan $\mathrm{KL} \mathrm{O-1}$ tersebut, kemudian menjelaskan bahwa pertanyaan mengenai komponen mental di dalam kuesioner SF-36 bersifat generik sehingga tidak terlalu sensitif untuk menentukan keberadaan gangguan kesehatan mental.
Selain itu, gangguan psikologis merupakan keadaan umum yang terjadi pada pasien OA yang dapat memengaruhi penurunan skor komponen mental.

\section{Simpulan}

Simpulan penelitian ini menunjukkan bahwa terdapat hubungan antara derajat nyeri dan kualitas hidup pasien dalam aspek nyeri tubuh dan vitalitas serta terdapat hubungan klasifikasi radiologik OA dengan kualitas hidup dalam aspek fungsi sosial pasien OA lutut.

\section{Ucapan Terima Kasih}

Terima kasih kepada pihak Pimpinan Rumah Sakit Al-Islam Bandung yang telah mengizinkan penelitian ini dilakukan pada para pasien OA lutut di bagian poliklinik penyakit dalam dan ortopedi.

\section{Daftar Pustaka}

1. Indonesian Rheumatology Association (IRA). Rekomendasi IRA untuk diagnosis dan penatalaksanaan osteoartritis. Jakarta: Indonesian Rheumatology Association; 2014.

2. World Health Organization. Osteoarthritis. World Health. 2013;12:6-8.

3. Litwic A, Edwards MH, Dennison EM, Cooper C. Epidemiology and burden of osteoarthritis. $\mathrm{Br}$ Med Bull. 2013;105:185-99.

4. Muraki S, Akune T, Oka H, En-yo Y, Yoshida M, Saika A, dkk. Association of radiographic and symptomatic knee osteoarthritis with healthrelated quality of life in a population-based cohort study in Japan: the ROAD study. Osteoarthr Cartil. 2010;18:1227-34.

5. Katz N. The impact of pain management on quality of life. J Pain Symptom Manage. 2002;24:38-47.

6. National Pharmaceutical Council (NPC). Pain: current understanding of assessment, management, and treatments [internet]. 2001 [diunduh 1 Agustus 2018]. Tersedia dari: https:// www.npcnow.org/system/files/research/ download/Pain-Current-Understanding-ofAssessment-Management-and-Treatments.pdf.

7. Burholt V, Nash P. Short form 36 (SF-36) Health Survey Questionnaire: normative data for Wales. J Public Health (Oxf). 2011;33(4):587-603.

8. Kiadaliri AA, Lamm CJ, de Verdier MG, Engström G, Turkiewicz A, Lohmander LS, dkk. Association of knee pain and different definitions of knee osteoarthritis with health-related quality of life : a population- based cohort study in southern Sweden. Health Qual Life Outcomes. 2016;14(1):121.

9. Lukum EM, Ilyas M, Murtala B, Liyadi F, Faridin HP. Hubungan derajat nyeri berdasarkan visual analogue scale (VAS) dengan derajat radiologik berdasarkan Kellgren Lawrence score pada foto konvensional lutut pasien osteoartritis sendi lutut. JST Kesehatan. 2011;1(1):1-10.

10. Kawano MM, Araújo ILA, Castro MC, Matos 
MA. Assessment of quality of life in patients with knee osteoarthritis. Acta Ortopédica Bras. 2015;23:307-10.

11. Sutbeyaz ST, Sezer N, Koseoglu BF, Ibrahimoglu $\mathrm{F}$, Tekin D. Influence of knee osteoarthritis on exercise capacity and quality of life in obese adults. Obesity (Silver Spring). 2007;15:2071-6.

12. Neogi $T$. The epidemiology and impact of pain in osteoarthritis. Osteoarthr Cartil. 2013;21:1145-53. 